\title{
उMR
}

\section{Association of NR4A1 and GNB2L1 genes with reproductive traits in commercial pig breeds}

\author{
T. Kumchoo ${ }^{1,2}$ and S. Mekchay ${ }^{3}$ \\ ${ }^{1}$ Human and Animal Biotechnology Program, Graduate School, \\ Chiang Mai University, Chiang Mai, Thailand \\ ${ }^{2}$ Center of Excellence on Agricultural Biotechnology (AG-BIO/PERDO-CHE), \\ Bangkok, Thailand \\ ${ }^{3}$ Department of Animal and Aquatic Sciences, Faculty of Agriculture, \\ Chiang Mai University, Chiang Mai, Thailand \\ Corresponding author: S. Mekchay \\ E-mail: supamit.m@cmu.ac.th \\ Genet. Mol. Res. 14 (4): 16276-16284 (2015) \\ Received August 12, 2015 \\ Accepted October 1, 2015 \\ Published December 8, 2015 \\ DOI http://dx.doi.org/10.4238/2015.December.8.18
}

ABSTRACT. The nuclear receptor subfamily 4 , group A, member 1 (NR4A1) and guanine nucleotide binding protein beta polypeptide 2 like-1 (GNB2L1) genes are expressed during the ovulatory process and in early pregnancy in pigs. The objective of this study was to analyze the effects of NR4A1 and GNB2L1 gene variants on reproductive traits in commercial pig breeds. Two single nucleotide polymorphisms (SNPs) of NR4A1 and GNB2L1 were identified by a polymerase chain reaction-restriction fragment length polymorphism method. Analysis of the association of these two SNPs with reproductive traits was evaluated in 515 commercial sows (273 Large White and 242 Landrace). The SNP NR4A1 g.3952A>G showed a significant association with the total number of piglets born, the number of piglets born alive, the number of piglets weaned alive, and the litter weight at weaning in the Landrace sows $(P<0.05)$. A significant association of SNP GNB2L1 g.2373T $>C$ with the litter weight at birth was observed in the Large White 
sows $(P<0.05)$. These results indicate that the porcine NR4A1 and GNB2L1 can be used as candidate genes for improvement of litter size traits in pigs.

Key words: NR4A1; GNB2L1; Reproductive trait; Litter size; Pig breeds

\section{INTRODUCTION}

Reproductive traits have a major effect on costs and economic returns in pig production (Martínez-Giner et al., 2013). Previous studies have indicated that long-term selection for ovulation rate and embryonic survival can successfully increase litter size in pigs (Johnson et al., 1999; Bertani et al., 2004; Gladney et al., 2004). Various genomic approaches have been used to identify candidate genes for increased ovulation rate and embryonic survival. These studies have shown that candidate genes for reproductive traits are typically expressed in ovarian follicles and the anterior pituitary gland (Bertani et al., 2004; Gladney et al., 2004). Five genes, follistatin (FST), nuclear receptor subfamily 4 , group A, member 1 (NR4A1), guanine nucleotide binding protein beta polypeptide 2 like-1 (GNB2L1), ferritin heavy-chain $(F T H)$, and follicle stimulation hormone beta subunit $(F S H B)$, are known to be differentially expressed between pig lines selected for improved reproductive traits and non-selected lines (Bertani et al., 2004; Gladney et al., 2004). To date, a few studies have used FST, FTH, and FSHB genes as a marker for determining reproductive improvement in pigs (Linville et al., 2001; Blowe et al., 2006; Lin et al., 2006; Pripwai and Mekchay, 2012). However, information on the association of NR4A1 and GNB2L1 with reproductive traits is limited. The present study was initiated to remedy this information deficit by examining the relationships of $N R 4 A 1$ and GNB2L1 with reproductive traits in sows.

NR4A1 (also known as nerve growth factor induced-B, NGFI-B) is an orphan nuclear receptor for a transcription factor, and plays a major role in the ovulatory process (Liu et al., 2011). The gene is rapidly and transiently induced by a luteinizing hormone surge in granulosa cells of preovulatory follicles in rats (Park et al., 2001) and humans (Havelock et al., 2005). The porcine NR4A1 gene is highly expressed in the ovary and uterus (Liu et al., 2011). Moreover, selection for increased levels of NR4A1 gene expression in ovarian follicles is related to an enhanced rate of ovulation and improved survival of embryos in pigs (Gladney et al., 2004). The porcine NR4A1 gene is localized on chromosome SSC5 (Genini et al., 2006) and contains six exons and five introns that encode a 202-amino acid protein (Liu et al., 2011). An A/G polymorphism in intron 5 of porcine NR4A1 was found to be significantly associated with the total number of piglets born (TNB) and number of piglets born alive (NBA) traits in pigs (Liu et al., 2011).

GNB2L1 encodes a guanine-nucleotide binding protein that acts as a receptor for activated C kinase proteins and has also been named RACK1 (Chou et al., 1999; Uenishi et al., 2004). The porcine GNB2L1 gene (GenBank accession No. NM_214332.1) has been successfully characterized. It is located on chromosome SSC5 (NCBI database, www.ncbi.nlm.nih.gov) and consists of eight exons and seven introns that encode a 317-amino acid protein (Chou et al., 1999). GNB2L1 is expressed in the pituitary gland, testis, ovaries, spleen, thymus, liver, kidney, and adrenal gland in mammalian species (Chou et al., 1999; Martínez-Giner et al., 2013). It has also been shown to be expressed in oocytes and preimplantation embryos of mice (Luria et al., 2000; Dehghani and Hahnel, 2005). Thus, it may be involved in oocyte and embryo development in mammals.

The information from previous studies indicates that NR4A1 and GNB2L1 could be candidate genes that could act as markers of reproductive traits in pigs. The aim of this study was to 
confirm this possibility by using NR4A1 and GNB2L1 polymorphisms to examine the association of these genes with reproductive traits in commercial pig breeds.

\section{MATERIAL AND METHODS}

\section{Animals and genomic DNA extraction}

Blood samples were taken from a total of 515 sows of the commercial pig breeds Large White $(\mathrm{N}=273)$ and Landrace $(\mathrm{N}=242)$. All sows were obtained from Betagro Hybrid International Company (Thailand). Reproductive performance of the sows was assessed in 2293 litters and was recorded in terms of TNB, NBA, number of piglets weaned alive (NWA), litter weight at birth (LWB, $\mathrm{kg}$ ), and litter weight at weaning ( 21 days, LWW, $\mathrm{kg}$ ). Genomic DNA samples were extracted by the Chelex method according to Walsh et al. (1991) and were kept at $4^{\circ} \mathrm{C}$ until analysis.

\section{Identification of single nucleotide polymorphisms (SNP) and genotyping}

SNP in the porcine NR4A1 gene was detected as described by Liu et al. (2011). To identify the SNP in the porcine GNB2L1 gene, primers were designed using nucleotide sequence information (GenBank accession No. AF146043; see Table 1). The primers covered the 5'-flanking region, exons and 3'-flanking region of the porcine GNB2L1 gene. Six DNA samples were selected from Large White sows with the three highest and three lowest TNB values and were amplified using each primer. Each amplicon was then directly sequenced using the CEQ 8000 Genetic Analysis System (Beckman-Coulter, USA) to identify SNPs in GNB2L1. The identified SNP (g.2373T $>C$ ) in GNB2L1 was used for the association study. Genotyping the SNPs of NR4A1 and GNB2L1 was carried out using the PCR-RFLP method. The PCR products were amplified in a total 20- $\mu \mathrm{L}$ volume containing $50 \mathrm{ng}$ genomic DNA sample, $1 \mathrm{X}\left(\mathrm{NH}_{4}\right)_{2} \mathrm{SO}_{4}$ buffer (Fermentas), $1.5 \mathrm{mM} \mathrm{MgCl}$, $0.2 \mathrm{mM}$ dNTPs, $0.4 \mu \mathrm{M}$ of each primer (Table 2), and $0.2 \mathrm{U}$ Taq DNA polymerase (Fermentas). The amplification conditions were as follows: $94^{\circ} \mathrm{C}$ for $3 \mathrm{~min}$ for initial denaturing and 40 cycles at $94^{\circ} \mathrm{C}$ for $30 \mathrm{~s}, 58^{\circ}-62^{\circ} \mathrm{C}$ for $30 \mathrm{~s}, 72^{\circ} \mathrm{C}$ for $45 \mathrm{~s}$, and a final extension at $72^{\circ} \mathrm{C}$ for $5 \mathrm{~min}$. The PCR fragments were digested with $0.25 \mathrm{U}$ restriction enzymes (Fermentas) as shown in Table 2. The digested PCR fragments were separated by electrophoresis on $6 \%$ polyacrylamide gels in $1 \mathrm{X}$ TBE buffer. The gels were visualized by ethidium bromide staining.

Table 1. Primer sequences used for SNP identification in the porcine GNB2L1 gene.

\begin{tabular}{|c|c|c|c|c|}
\hline Primers & Nucleotide sequences & Position* (Region) & Product size (bp) & $\operatorname{Tm}\left({ }^{\circ} \mathrm{C}\right)$ \\
\hline GNB2L1-1 & $\begin{array}{l}\text { F: 5'-ACTCTCCACAATACCTTAGG-3' } \\
\text { R: 5'-TGCTAAGGTGAACTATTAAAC-3' }\end{array}$ & $1402-1885$ (5'-flanking region) & 484 & $58^{\circ}$ \\
\hline GNB2L1-2 & $\begin{array}{l}\text { F: 5'-CAGAGCATAAACCTCTCCAG-3' } \\
\text { R: 5'-TGAGGAAAAGACCGAGCAG-3' }\end{array}$ & 1809-2341 (5'-flanking region) & 533 & $60^{\circ}$ \\
\hline GNB2L1-3 & $\begin{array}{l}\text { F: 5'-TTGAGCAGGAGTGCATTGTG-3' } \\
\text { R: 5'-ACGCACGGGTCAGCTCAC-3' }\end{array}$ & 2251-2668 (Exon 1) & 418 & $58^{\circ}$ \\
\hline GNB2L1-4 & $\begin{array}{l}\text { F: 5'-AATCACCTTGAGGTATCCTG-3' } \\
\text { R: 5'-CTCTTACACAGTGAACCTGA-3' }\end{array}$ & 3363-3734 (Exon 2) & 372 & $60^{\circ}$ \\
\hline GNB2L1-5 & $\begin{array}{l}\text { F: 5'-ATCCATAGTGTAACCAAGTC-3' } \\
\text { R: 5'-TATAAAAGGCCTACAACCTG-3' }\end{array}$ & 4120-4663 (Exon 3-4) & 544 & $58^{\circ}$ \\
\hline GNB2L1-6 & $\begin{array}{l}\text { F: 5'-CAGGTTTTTCACCTGTGACC-3' } \\
\text { R: 5'-CAGGTATTTGGCCTCAACTG-3' }\end{array}$ & 5146-5810 (Exon 5-6) & 665 & $60^{\circ}$ \\
\hline GNB2L1-7 & $\begin{array}{l}\text { F: 5'-AACTCTTGGCATCACAGCAC-3' } \\
\text { R: 5'-GACTACACTAACCTGATGAG-3' }\end{array}$ & 6340-7059 (Exon 7) & 720 & $58^{\circ}$ \\
\hline
\end{tabular}

${ }^{*}$ Nucleotide position based on sequence information in GenBank accession No. AF146043. 
Table 2. Primer sequences, PCR conditions, and restriction enzymes used for genotyping of porcine NR4A1 and GNB2L1 genes.

\begin{tabular}{llccc}
\hline SNPs & Primer sequences & $\operatorname{Tm}\left({ }^{\circ} \mathrm{C}\right)$ & Product size $(\mathrm{bp})$ & Restriction enzyme \\
\hline NR4A1 & F: $5^{\prime}$-TTCCTCTGGGTCACAACG-3' & $58^{\circ}$ & 128 & Ddel \\
GNB2L1 $1^{\mathrm{b}}$ & R: $5^{\prime}$-CTCACAGAGTCAATGCCG-3' & & & Taql \\
& F: $5^{\prime}$-'TGAGCAGGAGTGCATTGTG-3' & $62^{\circ}$ & 143 & \\
\hline
\end{tabular}

a Liu et al. (2011), 'Mismatch base is underlined to generate a recognition site of the restriction enzyme Taql for genotyping.

\section{Statistical analysis}

Genotype and allele frequencies were calculated. Hardy-Weinberg equilibrium was tested using the chi-square analysis. The analysis of the association of the NR4A1 and GNB2L1 genes with reproductive traits was performed using a general linear model (GLM) with the SAS software, version 6.08 (SAS Institute, Inc., Carry, NC, USA). The following statistical model was used: $Y_{i j k l}=$ $\mu+P_{i}+Y S_{j}+G_{k}+e_{i j k l}$, where $Y_{i j k l}$ is representative of the observations of the phenotype values, $\mu$ represents the average normalized record of populations, $P_{i}$ represents the fixed effect of parities $(i=1-5), Y_{j}$ represents the fixed effect of year-season $(j=1-8), G_{k}$ is representative of the fixed effect of the genotypes $(k=1-3)$, and $e_{i j k l}$ represents the residual error. Additive and dominant effects were calculated according to Lin et al. (2006). Significance of the effects was tested by $t$-tests for deviation from zero.

\section{RESULTS}

\section{Polymorphisms of NR4A1 and GNB2L1 genes}

The $A>G$ polymorphism in intron 5 of the porcine NR4A1 gene was reported in a previous study (Liu et al., 2011) and, using the standard mutation nomenclature, named g.3952A>G based on the available nucleotide sequence information (GenBank accession No. NG_013208.1). The NR4A1 g.3952A>G SNP was digested with the restriction enzyme Ddel and two specific alleles were identified, a 128-bp fragment for allele $A$, and two fragments of 93 and 35 bp for allele $G$. A novel SNP GNB2L1 g.2373T>C was found in the 5'-flanking region and was also detected with the restriction enzyme Taql. Two specific alleles were found to be a 143-bp fragment for allele $T$ and two fragments of 122 and $21 \mathrm{bp}$ for allele $\mathrm{C}$. These two polymorphisms were segregating in the commercial pig breeds. The three different genotype patterns for SNPs NR4A1 g.3952A $>\mathrm{G}$ and GNB2L1 g.2373T>C loci among commercial pig breeds are shown in Figures 1 and 2, respectively.

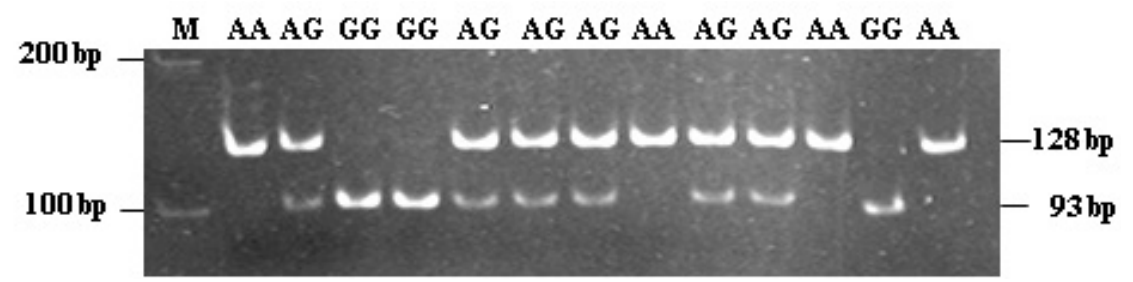

Figure 1. PCR-RFLP test for the SNP NR4A1 g.3952A>G locus after digestion with the restriction enzyme Ddel. Lane $M=100-b p$ DNA ladder. NR4A1 genotypes are given at the top of each line. 


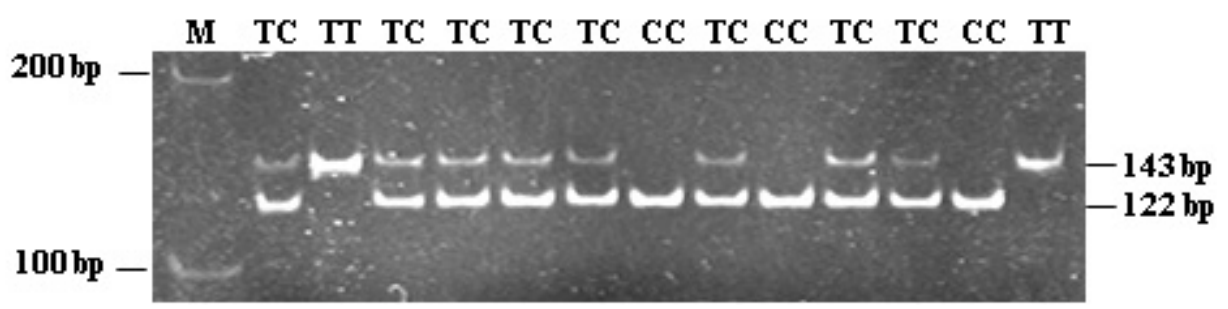

Figure 2. PCR-RFLP test for the SNP GNB2L1 g.2373T>C locus after digestion with the restriction enzyme Taql. Lane $M=100-b p$ DNA ladder. GNB2L1 genotypes are given at the top of each line.

\section{Genotype and allele frequencies}

All genotype and allele frequencies of the porcine NR4A1 and GNB2L1 genes of two commercial pig breeds are shown in Table 3 . The chi-square $\left(\chi^{2}\right)$ test showed that all genotypes for each locus of the porcine NR4A1 and GNB2L1 genes in the two commercial pig breeds were in Hardy-Weinberg equilibrium ( $P>0.05)$, except for the SNP NR4A1 g.3952A $>G$ of the Large White pigs, which deviated significantly from the Hardy-Weinberg equilibrium $(P<0.05)$. At the NR4A1 g.3952A>G locus, the NR4A1 g.3952A allele was more frequent in the two commercial pig breeds. At the GNB2L1 g.2373T>C locus, the GNB2L1 g.2373T allele was the major allele in Landrace sows. The GNB2L1 g.2373T allele was found to be a minor allele among Large White sows.

Table 3. Genotype and allele frequencies of the porcine NR4A1 and GNB2L1 genes in commercial pig breeds.

\begin{tabular}{|c|c|c|c|c|c|c|c|}
\hline \multirow[t]{2}{*}{ SNPs } & \multirow[t]{2}{*}{ Breed } & \multicolumn{3}{|c|}{ Genotype frequency } & \multicolumn{2}{|c|}{ Allele frequency ${ }^{1}$} & \multirow[t]{2}{*}{ P value ${ }^{2}\left(\chi^{2}\right)$} \\
\hline & & AA & $A B$ & BB & $f(A)$ & $f(B)$ & \\
\hline \multirow[t]{2}{*}{$N R 4 A 1(\mathrm{~g} .3952 \mathrm{~A}>\mathrm{G})$} & Large white & 0.44 & 0.37 & 0.19 & 0.62 & 0.38 & $0.039^{\star}$ \\
\hline & Landrace & 0.69 & 0.28 & 0.03 & 0.83 & 0.17 & 0.839 \\
\hline \multirow[t]{2}{*}{ GNB2L1 (g.2373T>C) } & Large white & 0.12 & 0.45 & 0.43 & 0.35 & 0.65 & 0.994 \\
\hline & Landrace & 0.38 & 0.46 & 0.16 & 0.61 & 0.39 & 0.931 \\
\hline
\end{tabular}

${ }^{1}$ Allele A represents wild-type alleles of the NR4A1 g.3952A and GNB2L1 g.2373T loci, respectively and allele B represents mutant alleles of the NR4A1 g.3952G and GNB2L1 g.2373C loci, respectively. ${ }^{2}$ The $P$ value is considered a significant level of the chi-square $\left(\chi^{2}\right)$ test for Hardy-Weinberg equilibrium of each locus in different pig breeds, ${ }^{*} P<0.05$.

\section{Associations of NR4A1 and GNB2L1 polymorphisms with reproductive traits}

The association of the NR4A1 and GNB2L1 genes with reproductive traits is shown in Tables 4 and 5. There was no significant association of the NR4A1 g.3952A>G SNP with any reproductive trait in Large White and Landrace sows at first parity. At later parities, the NR4A1 g.3952A>G SNP was significantly associated with the TNB, NBA, NWA, and LWW traits in the Landrace sows $(P<0.05)$. Sows with the $A A$ and $A G$ genotypes had significantly higher TNB, NBA, NWA, and LWW values than with the GG genotype. Moreover, significant additive and dominant effects on the reproductive traits were observed in the Landrace sows (Table 4). No association was found in Large White sows for the NR4A1 g.3952A>G SNP and any reproductive trait. No association of the GNB2L1 g.2373T>C SNP was found with any reproductive trait in both breeds at first parity. GNB2L1 g.2373T >C did show a significant association with the LWB trait at later parities in Large White sows $(P<0.05)$. Sows with the $C C$ genotype had significantly higher LWB values 
than those of sows with the TT and TC genotypes. Moreover, significant additive and dominant effects of the GNB2L1 g.2373T>C SNP were found for reproductive traits in Large White and Landrace sows (Table 5).

Table 4. Association of the g.3952A $>\mathrm{G}$ locus of the porcine $N R 4 A 1$ gene with reproductive traits in commercial pig breeds.

\begin{tabular}{|c|c|c|c|c|c|c|c|}
\hline \multirow[t]{2}{*}{ Breed } & \multirow[t]{2}{*}{ Parity } & \multirow[t]{2}{*}{ Trait $^{1}$} & \multicolumn{3}{|c|}{ Genotype (means \pm SE) $)^{2}$} & \multirow[t]{2}{*}{ Additive } & \multirow[t]{2}{*}{ Dominant } \\
\hline & & & AA & AG & GG & & \\
\hline \multirow[t]{10}{*}{ Large White } & \multirow[t]{5}{*}{ First parity } & TNB & $10.89 \pm 0.46$ & $11.43 \pm 0.49$ & $11.66 \pm 0.58$ & $-0.38 \pm 0.37$ & $0.15 \pm 0.59$ \\
\hline & & NBA & $9.27 \pm 0.45$ & $9.92 \pm 0.48$ & $9.92 \pm 0.66$ & $-0.32 \pm 0.37$ & $0.32 \pm 0.58$ \\
\hline & & NWA & $8.57 \pm 0.43$ & $8.90 \pm 0.46$ & $8.87 \pm 0.63$ & $-0.15 \pm 0.35$ & $0.18 \pm 0.55$ \\
\hline & & LWB & $12.81 \pm 0.59$ & $13.48 \pm 0.64$ & $13.62 \pm 0.86$ & $-0.40 \pm 0.48$ & $0.27 \pm 0.76$ \\
\hline & & LWW & $57.48 \pm 2.74$ & $59.34 \pm 2.92$ & $58.22 \pm 3.99$ & $-0.37 \pm 2.23$ & $1.49 \pm 3.49$ \\
\hline & \multirow[t]{5}{*}{ Later parities } & TNB & $11.11 \pm 0.67$ & $11.19 \pm 0.64$ & $11.52 \pm 0.77$ & $-0.21 \pm 0.28$ & $-0.13 \pm 0.42$ \\
\hline & & NBA & $9.83 \pm 0.61$ & $9.64 \pm 0.58$ & $10.16 \pm 0.70$ & $-0.17 \pm 0.25$ & $-0.36 \pm 0.38$ \\
\hline & & NWA & $9.00 \pm 0.59$ & $8.79 \pm 0.56$ & $9.52 \pm 0.67$ & $-0.26 \pm 0.24$ & $-0.46 \pm 0.37$ \\
\hline & & LWB & $14.65 \pm 0.86$ & $14.04 \pm 0.81$ & $14.98 \pm 0.98$ & $-0.17 \pm 0.35$ & $-0.78 \pm 0.54$ \\
\hline & & LWW & $59.65 \pm 3.75$ & $57.94 \pm 3.56$ & $62.15 \pm 4.30$ & $-1.25 \pm 1.56$ & $-2.96 \pm 2.36$ \\
\hline \multirow[t]{10}{*}{ Landrace } & \multirow[t]{5}{*}{ First parity } & TNB & $9.76 \pm 0.47$ & $9.22 \pm 0.50$ & $9.23 \pm 1.09$ & $0.27 \pm 0.52$ & $-0.28 \pm 0.64$ \\
\hline & & NBA & $8.53 \pm 0.52$ & $7.94 \pm 0.55$ & $8.35 \pm 1.21$ & $0.09 \pm 0.58$ & $-0.50 \pm 0.71$ \\
\hline & & NWA & $7.86 \pm 0.51$ & $7.62 \pm 0.54$ & $7.67 \pm 1.19$ & $0.09 \pm 0.56$ & $-0.15 \pm 0.69$ \\
\hline & & LWB & $13.39 \pm 0.67$ & $12.46 \pm 0.71$ & $12.86 \pm 1.55$ & $0.26 \pm 0.74$ & $-0.66 \pm 0.91$ \\
\hline & & LWW & $52.94 \pm 2.90$ & $50.40 \pm 3.08$ & $50.27 \pm 6.70$ & $1.34 \pm 3.19$ & $-1.20 \pm 3.95$ \\
\hline & \multirow[t]{5}{*}{ Later parities } & TNB & $11.00 \pm 0.33^{b}$ & $11.51 \pm 0.36^{b}$ & $9.37 \pm 0.84^{a}$ & $0.82 \pm 0.40^{*}$ & $1.32 \pm 0.48^{* \star}$ \\
\hline & & NBA & $9.51 \pm 0.35^{b}$ & $10.01 \pm 0.38^{b}$ & $7.59 \pm 0.88^{\mathrm{a}}$ & $0.96 \pm 0.42^{*}$ & $1.46 \pm 0.50^{\star *}$ \\
\hline & & NWA & $8.71 \pm 0.33^{b}$ & $9.46 \pm 0.36^{c}$ & $6.94 \pm 0.83^{a}$ & $0.88 \pm 0.39^{*}$ & $1.64 \pm 0.47^{\star \star \star x}$ \\
\hline & & LWB & $15.31 \pm 0.47$ & $16.18 \pm 0.51$ & $13.20 \pm 1.22$ & $1.06 \pm 0.59$ & $1.92 \pm 0.69$ \\
\hline & & LWW & $58.05 \pm 2.00^{b}$ & $63.46 \pm 2.17^{c}$ & $47.78 \pm 5.17^{a}$ & $5.14 \pm 2.48^{*}$ & $10.54 \pm 2.92^{* k *}$ \\
\hline
\end{tabular}

${ }^{1} \mathrm{LWB}$ and LWW traits are reported in $\mathrm{kg} .{ }^{2}$ Means $\pm \mathrm{SE}$ represent least square means \pm standard error. Values in each row with different superscripts are significantly different $(P<0.05),{ }^{*} P<0.05 ;{ }^{* *} P<0.01 ;{ }^{* * *} P<0.001$.

Table 5. Association of the g.2373T>C locus of the porcine GNB2L1 gene with reproductive traits in commercial pig breeds.

\begin{tabular}{|c|c|c|c|c|c|c|c|}
\hline \multirow[t]{2}{*}{ Breed } & \multirow[t]{2}{*}{ Parity } & \multirow[t]{2}{*}{ Trait $^{1}$} & \multicolumn{3}{|c|}{ Genotype (means \pm SE) $)^{2}$} & \multirow[t]{2}{*}{ Additive } & \multirow[t]{2}{*}{ Dominant } \\
\hline & & & TT & $\mathrm{TC}$ & $\mathrm{CC}$ & & \\
\hline \multirow[t]{10}{*}{ Large White } & \multirow[t]{5}{*}{ First parity } & TNB & $12.12 \pm 0.82$ & $10.86 \pm 0.44$ & $11.33 \pm 0.45$ & $0.40 \pm 0.45$ & $-0.86 \pm 0.60$ \\
\hline & & NBA & $10.93 \pm 0.79$ & $9.06 \pm 0.43$ & $9.79 \pm 0.43$ & $0.57 \pm 0.43$ & $-1.30 \pm 0.58^{*}$ \\
\hline & & NWA & $9.60 \pm 0.76$ & $8.27 \pm 0.41$ & $8.86 \pm 0.41$ & $0.37 \pm 0.41$ & $-0.96 \pm 0.55$ \\
\hline & & LWB & $14.67 \pm 1.03$ & $12.54 \pm 0.56$ & $13.40 \pm 0.57$ & $0.63 \pm 0.56$ & $-1.50 \pm 0.76^{*}$ \\
\hline & & LWW & $63.74 \pm 4.72$ & $55.05 \pm 2.56$ & $58.84 \pm 2.63$ & $2.45 \pm 2.58$ & $-6.25 \pm 3.47$ \\
\hline & \multirow[t]{5}{*}{ Later parities } & TNB & $10.04 \pm 0.83$ & $10.85 \pm 0.64$ & $11.68 \pm 0.63$ & $-0.82 \pm 0.32^{\star *}$ & $-0.01 \pm 0.43$ \\
\hline & & NBA & $8.89 \pm 0.77$ & $9.55 \pm 0.60$ & $10.12 \pm 0.58$ & $-0.61 \pm 0.30^{*}$ & $0.04 \pm 0.40$ \\
\hline & & NWA & $8.47 \pm 0.75$ & $8.65 \pm 0.58$ & $9.23 \pm 0.56$ & $-0.38 \pm 0.29$ & $-0.20 \pm 0.39$ \\
\hline & & LWB & $13.18 \pm 1.07^{\mathrm{a}}$ & $13.84 \pm 0.83^{a}$ & $14.96 \pm 0.81^{b}$ & $-0.89 \pm 0.41^{*}$ & $-0.23 \pm 0.55$ \\
\hline & & LWW & $55.48 \pm 4.79$ & $56.77 \pm 3.69$ & $61.07 \pm 3.59$ & $-2.79 \pm 1.86$ & $-1.50 \pm 2.48$ \\
\hline \multirow[t]{10}{*}{ Landrace } & \multirow[t]{5}{*}{ First parity } & TNB & $9.62 \pm 0.51$ & $9.68 \pm 0.49$ & $8.87 \pm 0.57$ & $0.37 \pm 0.28$ & $0.43 \pm 0.41$ \\
\hline & & NBA & $8.37 \pm 0.57$ & $8.48 \pm 0.55$ & $7.62 \pm 0.64$ & $0.38 \pm 0.32$ & $0.48 \pm 0.45$ \\
\hline & & NWA & $7.96 \pm 0.56$ & $7.94 \pm 0.53$ & $6.97 \pm 0.63$ & $0.50 \pm 0.31$ & $0.48 \pm 0.44$ \\
\hline & & LWB & $13.06 \pm 0.73$ & $13.16 \pm 0.70$ & $12.19 \pm 0.83$ & $0.44 \pm 0.42$ & $0.54 \pm 0.59$ \\
\hline & & LWW & $52.13 \pm 3.20$ & $51.76 \pm 3.04$ & $49.47 \pm 3.72$ & $1.33 \pm 1.90$ & $0.97 \pm 2.62$ \\
\hline & \multirow[t]{5}{*}{ Later parities } & TNB & $11.26 \pm 0.35$ & $11.34 \pm 0.36$ & $10.59 \pm 0.45$ & $0.34 \pm 0.22$ & $0.41 \pm 0.30$ \\
\hline & & NBA & $9.65 \pm 0.36$ & $9.81 \pm 0.38$ & $9.26 \pm 0.46$ & $0.19 \pm 0.23$ & $0.35 \pm 0.32$ \\
\hline & & NWA & $8.78 \pm 0.35$ & $9.13 \pm 0.36$ & $8.70 \pm 0.44$ & $0.04 \pm 0.21$ & $0.39 \pm 0.30$ \\
\hline & & LWB & $15.82 \pm 0.49$ & $15.86 \pm 0.51$ & $14.31 \pm 0.62$ & $0.76 \pm 0.30^{* *}$ & $0.80 \pm 0.43$ \\
\hline & & LWW & $60.07 \pm 2.10$ & $60.44 \pm 2.20$ & $57.31 \pm 2.67$ & $1.38 \pm 1.30$ & $1.75 \pm 1.84$ \\
\hline
\end{tabular}

${ }^{1} \mathrm{LWB}$ and LWW traits are reported in $\mathrm{kg} .{ }^{2}$ Means $\pm \mathrm{SE}$ represent least square means \pm standard error. Values in each row with different superscripts are significantly different $(P<0.05)$, ${ }^{*} P<0.05$; ${ }^{* *} P<0.01$. 


\section{DISCUSSION}

Litter size plays an important role in the profitability of the pig industry (Marantidis et al., 2013). Identification of single genes with large effects on quantitative traits provides a clear opportunity to improve the accuracy of selection for litter size (Short et al., 1997). Several association analyses have been carried out and candidate genes (BF, ESR, FSHB, FST, LIF, $P P A R \gamma, P R L R$, and RBP4) with effects on reproductive traits have been identified in commercial pig breeds (Rothschild et al., 1996, 2000; Drögemüller et al., 2001; Buske et al., 2005; Spötter et al., 2005, 2009; Blowe et al., 2006; Lin et al., 2006; Wang et al., 2011; Marantidis et al., 2013). In the present study, we examined polymorphisms of the porcine NR4A1 and GNB2L1 genes with respect to reproductive traits. The $N R 4 A 1 \mathrm{~g} .3952 \mathrm{~A}>\mathrm{G}$ and $G N B 2 L 1 \mathrm{~g} .2373 T>C$ SNPs were found to segregate in the Large White and Landrace sows. All three possible genotypes were observed in both commercial pig breeds. NR4A1 g.3952A was the major allele in the Large White and Landrace sows. This result is consistent with a previous study, which showed that the NR4A1 g.3952A allele was dominant among Large White pigs and DIV (a synthetic line) sows (Liu et al., 2011). GNB2L1 g.2373T was the major allele in Landrace sows but was a minor allele in Large White sows. The results of the chi-square test showed that the NR4A1 g.3952A>G SNP in Landrace sows met the Hardy-Weinberg equilibrium specifications whereas among the Large White sows it showed a significant deviation from Hardy-Weinberg equilibrium. GNB2L1 g.2373T>C was in HardyWeinberg equilibrium in both Large White and Landrace sows. The results indicated that there was a large selection pressure on NR4A1 g.3952A>G in the Large White sows, and that GNB2L1 g.2373T $>C$ of Large White and Landrace sows was under homeostasis when accompanied by artificial selection.

The association study showed that NR4A1 and GNB2L1 influenced reproductive traits. NR4A1 g.3952A>G showed significant associations with TNB, NBA, NWA, and LWW traits in Landrace sows at later parities. Landrace sows with AA or AG genotypes had larger litter sizes. No association was found between NR4A1 g.3952A $>G$ and any reproductive trait in Large White sows. These results are inconsistent with a previous study, which indicated that the NR4A1 g.3952A>G had significant associations with TNB and NBA traits in the Large White pig and DIV sows. Sows with AG or GG genotypes had larger litter sizes (Liu et al., 2011). The inconsistent results of these studies indicate that different linkage relationships exist across populations. Moreover, NR4A1 g.3952A>G may have lower linkage disequilibrium with the causative mutation in this Large White population. The NR4A1 gene is a nuclear steroid hormone receptor and is expressed in the ovarian follicle and ovary (Park et al., 2001) and plays an important role in the regulation of steroid signaling and follicle maturation (Havelock et al., 2005; Li et al., 2010; Dai et al., 2012). It has been reported that increased expression of NR4A1 in pigs under selection for enhanced ovulation rate and embryonic survival may be correlated with an increased sensitivity to steroid hormones in ovarian follicles (Gladney et al., 2004). In the present study, the significant association identified between NR4A1 and litter size traits indicated that this gene would be expected to play an important function in the litter size traits of pigs.

The GNB2L1 g.2373T>C SNP showed significant association with the LWB trait in Large White sows. This SNP also displayed significant additive and dominant effects for TNB, NBA, and LWB traits in Large White sows. Similarly, GNB2L1 g.2373T >C showed a significant additive effect for the LWB trait in Landrace sows. The GNB2L1 gene is a receptor for activated C kinase proteins (Chou et al., 1999). It is expressed in oocytes and preimplantation embryos of mammals (Luria et al., 
2000; Dehghani and Hahnel, 2005). Selection for enhanced ovulation rate and embryonic survival caused a decrease in the expression level of GNB2L1 in the pituitary gland of sows (Bertani et al., 2004). However, there is no evidence that long-term selection for increased ovulation rate and embryo survival altered the expression level of the GNB2L1 gene in porcine ovarian follicles. The present study showed the association of GNB2L1 g.2373T>C with reproductive traits in pigs. Our results indicate that the GNB2L1 gene plays an important role in the function of the reproductive traits of pigs. Further association analyses on NRAA1 and GNB2L1 genes in a larger population sample are required. Moreover, the effects of the GNB2L1 polymorphisms on mRNA and protein expression levels in target tissues need to be examined.

In conclusion, we found that polymorphisms of porcine NR4A1 and GNB2L1 genes have different patterns of association with reproductive traits. The SNPs NR4A1 g.3952A $>\mathrm{G}$ and GNB2L1 g.2373T>C had clear effects on TNB, NBA, NWA, LWB, and LWW traits in commercial pig breeds. The results indicate the importance of the NR4A1 and GNB2L1 genes in the reproductive traits of pigs. Therefore, these two SNPs may be used as candidate marker genes for genetic improvement of litter size in pig breeding.

\section{Conflicts of interest}

The authors declare no conflict of interest.

\section{ACKNOWLEDGMENTS}

Research partially supported by the Center of Excellence on Agricultural Biotechnology, Science and Technology Postgraduate Education and Research Development Office, Office of Higher Education Commission, Ministry of Education (AG-BIO/PERDO-CHE) and the National Center for Genetic Engineering and Biotechnology, National Science and Technology Development Agency, Ministry of Science and Technology (BT-B-01-AG-10-5002). We would like to thank the Betagro Hybrid International Company, Thailand, for providing blood samples of the two commercial pig breeds used in this study.

\section{REFERENCES}

Bertani GR, Gladney CD, Johnson RK and Pomp D (2004). Evaluation of gene expression in pigs selected for enhanced reproduction using differential display PCR: II. Anterior pituitary. J. Anim. Sci. 82: 32-40.

Blowe CD, Boyette KE, Ashwell MS, Eisen EJ, et al. (2006). Characterization of a line of pigs previously selected for increased litter size for RBP4 and follistatin. J. Anim. Breed. Genet. 123: 389-395.

Buske B, Brunsch C, Zeller K, Reinecke P, et al. (2005). Analysis of properdin (BF) genotypes associated with litter size in a commercial pig cross population. J. Anim. Breed. Genet. 122: 259-263.

Chou YC, Chou CC, Chen YK, Tsai S, et al. (1999). Structure and genomic organization of porcine RACK1 gene. Biochim. Biophys. Acta 1489: 315-322.

Dai A, Yan G, He Q, Jiang Y, et al. (2012). Orphan nuclear receptor nur77 regulates androgen receptor gene expression in mouse ovary. PLoS One 7: e39950.

Dehghani $\mathrm{H}$ and Hahnel AC (2005). Expression profile of protein kinase C isozymes in preimplantation mouse development. Reproduction 130: 441-451.

Drögemüller C, Hamann H and Distl O (2001). Candidate gene markers for litter size in different German pig lines. J. Anim. Sci. 79: 2565-2570.

Genini S, Nguyen TT, Malek M, Talbot R, et al. (2006). Radiation hybrid mapping of 18 positional and physiological candidate genes for arthrogryposis multiplex congenita on porcine chromosome 5. Anim. Genet. 37: 239-244. 
Gladney CD, Bertani GR, Johnson RK and Pomp D (2004). Evaluation of gene expression in pigs selected for enhanced reproduction using differential display PCR and human microarrays: I. Ovarian follicles. J. Anim. Sci. 82: 17-31.

Havelock JC, Smith AL, Seely JB, Dooley CA, et al. (2005). The NGFI-B family of transcription factors regulates expression of 3b-hydroxysteroid dehydrogenase type 2 in the human ovary. Mol. Hum. Reprod. 11: 79-85.

Johnson RK, Nielsen MK and Casey DS (1999). Responses in ovulation rate, embryonal survival, and litter traits in swine to 14 generations of selection to increase litter size. J. Anim. Sci. 77: 541-557.

Li M, Xue K, Ling J, Diao FY, et al. (2010). The orphan nuclear receptor NR4A1 regulates transcription of key steroidogenic enzymes in ovarian theca cells. Mol. Cell. Endocrinol. 319: 39-46.

Lin CL, Ponsuksili S, Tholen E, Jennen DGJ, et al. (2006). Candidate gene markers for sperm quality and fertility of boar. Anim. Reprod. Sci. 92: 349-363.

Linville RC, Pomp D, Johnson RK and Rothschild MF (2001). Candidate gene analysis for loci affecting litter size and ovulation rate in swine. J. Anim. Sci. 79: 60-67.

Liu LQ, Li FE, Deng CY and Xiong YZ (2011). Molecular cloning, tissue expression and association of porcine NR4A1 gene with reproductive traits. Mol. Biol. Rep. 38: 103-114.

Luria A, Tennenbaum T, Sun QY, Rubinstein S, et al. (2000). Differential localization of conventional protein kinase C isoforms during mouse oocyte development. Biol. Reprod. 62: 1564-1570.

Marantidis A, Papadopoulos Al, Michailidis G and Avdi M (2013). Association of BF gene polymorphism with litter size in a commercial pig cross population. Anim. Reprod. Sci. 141: 75-79.

Martínez-Giner M, Noguera JL, Balcells I, Fernández-Rodríguez A, et al. (2013). Selection of internal control genes for realtime quantitative PCR in ovary and uterus of sows across pregnancy. PLoS One 8: e66023.

Park JI, Park HG, Chol HK, Lee K, et al. (2001). Gonadotropin regulation of NGFI-B messenger ribonucleic acid expression during ovarian follicle development in the rat. Endocrinology 142: 3051-3059.

Pripwai N and Mekchay S (2012). Haplotype analysis of ferritin heavy chain affects stillborn piglets on Large White X Landrace crossbred sows. J. Agric. Sci. 4: 62-70.

Rothschild MF, Jacobson C, Vaske D, Tuggle C, et al. (1996). The estrogen receptor locus is associated with a major gene influencing litter size in pigs. Proc. Natl. Acad. Sci. U. S. A. 93: 201-205.

Rothschild MF, Messer L, Day A, Wales R, et al. (2000). Investigation of the retinol-binding protein 4 (RBP4) gene as a candidate gene for increased litter size in pigs. Mamm. Genome 11: 75-77.

Short TH, Rothschild MF, Southwood OI, McLaren DG, et al. (1997). Effect of the estrogen receptor locus on reproduction and production traits in four commercial pig lines. J. Anim. Sci. 75: 3138-3142.

Spötter A, Drögemüller C, Hamann C and Distl O (2005). Evidence of a new leukemia inhibitory factor-associated genetic marker for litter size in a synthetic pig line1. J. Anim. Sci. 83: 2264-2270.

Spötter A, Muller S, Hamann H and Distl O (2009). Effect of polymorphisms in the genes for LIF and RBP4 on litter size in two German pig lines. Reprod. Domest. Anim. 44: 100-105.

Uenishi H, Eguchi T, Suzuki K, Sawazaki T, et al. (2004). PEDE (Pig EST Data Explorer): construction of a database for ESTs derived from porcine full-length cDNA libraries. Nucleic Acids Res. 32: D484-D488.

Walsh PS, Metzger DA and Higuchi R (1991). Chelex 100 as a medium for simple extraction of DNA for PCR-based typing from forensic material. Biotechniques 10: 506-513.

Wang G, Kong L, Hu P, Fu J and Wang A (2011). Effect of polymorphism in the peroxisome proliferator-activated receptor gamma gene on litter size of pigs. Mol. Biol. Rep. 38: 1807-1812. 